University of St. Thomas, Minnesota

UST Research Online

Communication and Journalism Faculty

Publications

Communication and Journalism

2008

Being Aristotelian: Using Virtue Ethics in an Applied Media Ethics

Course

Wendy N. Wyatt

University of St. Thomas, Minnesota, wnwyatt@stthomas.edu

Follow this and additional works at: https://ir.stthomas.edu/cas_cojo_pub

Part of the Ethics and Political Philosophy Commons, Journalism Studies Commons, and the Mass

Communication Commons

This Article is brought to you for free and open access by the Communication and Journalism at UST Research Online. It has been accepted for inclusion in Communication and Journalism Faculty Publications by an authorized administrator of UST Research Online. For more information, please contact asle4660@stthomas.edu. 


\section{Being Aristotelian: \\ Using virtue ethics in an applied media ethics course}

This essay explores the tendency of undergraduate media ethics students to do what Bernard Gert calls "morality by slogans" and their tendency to misuse Aristotle's golden mean slogan. While not solving the dilemma of morality by slogans, the essay suggests some ways of rectifying the misuse of the golden mean and encouraging its more authentic application.

Any professor of media ethics knows the dangers of teaching ethical theory to undergraduates. In 15 weeks or fewer, students work not only to develop skills in ethical analysis — in which theory is only one part—but they also explore recurring moral issues, they reflect on what they can do to make their profession better, and they think about their roles and responsibilities as media consumers. Theory, then, often gets reduced to slogans. John Stuart Mill becomes simply "the greatest good for the greatest number" guy. Kant gets two slogans: "Don't make yourself an exception to the rule," and "don't treat people as only a means." And Aristotle, for many students, is "Mr. Golden Mean." (Actually, Aristotle is often confused as "Mr. Golden Rule," but that's another frustration altogether.)

Among others, Bernard Gert has recognized this tendency to reduce morality to slogans. ${ }^{1}$ In his article, "Morality versus Slogans," Gert critiques—-he actually says "attacks" - the golden rule, the categorical imperative and the ten commandments, arguing that the slogans associated with these moral dictums lead to simplistic thinking about morality. Gert offers "an attack on the view that you can summarize morality in a

\footnotetext{
${ }^{1}$ Thanks to Deni Elliott who first introduced me to the idea of morality by slogans.
} 
one-sentence, or maybe a ten-sentence, slogan." ${ }^{2}$ Moral theory, he says, is an attempt to get beyond slogans.

I wholeheartedly support Gert's perspective. But how do teachers of ethics help their students, many of whom are being introduced to moral theory for the first time, transcend slogans and develop enough theoretical literacy to adequately apply the ideas?

This paper will not solve the dilemma of students doing morality by slogans, but it will attempt to explore the misuse of one particular slogan and suggest some ways toif not stop students from using the slogan altogether—at least rectify its misuse. The theorist? Aristotle. And the slogan? The golden mean.

\section{(Mis)applying Aristotle}

Consider this Aristotelian analysis — or misanalysis—of a media ethics dilemma. Here, a group of students is trying to decide whether an ad campaign created by the Los Angeles Gay and Lesbian Center is ethically justifiable. Each of the campaign's ads features the headline "HIV is a gay disease" and the tagline "Own it. End it." The center developed the campaign in response to two things: 1) statistics that show three out of four people living with HIV/AIDS in Los Angeles are gay or bisexual men and 2) a silence surrounding the topic of HIV that members of the center called "deadening." "The campaign was embraced by some in Los Angeles as a necessary means of spurring action; by others it was condemned as unethical, as a tactic that took views on HIV back in time 20 years. ${ }^{4}$

\footnotetext{
${ }^{2}$ Bernard Gert, Morality versus Slogans (Paper Presented to the Center for the Study of Ethics in Society, Western Michigan University, Kalamazoo, Michigan, 1989): 115.

${ }^{3}$ See "HIV is not a gay disease," editorial, Gay \& Lesbian Times (12 Oct. 2006) 1 Feb. 2008 $<$ http://www.gaylesbiantimes.com/?id=8282>

${ }^{4}$ Sharon Bernstein, "HIV Ads Embrace, and Stun, Audience," Los Angeles Times (30 Sept., 2006): A1.
} 
In addition to considering other theoretical perspectives, students often pose the Aristotelian question: Are the creators of the ads finding the golden mean with this campaign? In analyzing the question, students argue that they should rule out the excess - running the campaign as it was conceived — and the deficiency — not running the campaign at all. The mean, therefore, falls somewhere between these two and typically ends up being a recommendation by students to do a "less shocking" version of the campaign that features a different headline and tagline.

Are the students justified in their ultimate recommendation? Perhaps so, but it is not the recommendation I find misguided. Rather, it's the means of arriving at the recommendation, the application of the golden mean concept. Aristotle's golden mean is not about doing; it's about being. Character traits—or virtues—are represented by the golden mean, not behaviors. So when students say they need to figure out what action hits the mark of the golden mean, they are missing the point of Aristotle, as well as a fundamental difference between him and other moral philosophers typically covered in a media ethics course. In this case, the slogan has failed them.

\section{$\underline{\text { An earlier critique }}$}

This paper is not the first on the topic. In 1999, Stanley Cunningham wrote an article for the Journal of Mass Media Ethics titled "Getting it Right: Aristotle's 'Golden Mean' as Theory Deterioration." In it, Cunningham argues that the golden mean "is a bad paraphrase and even worse ethical theory" and that its misapplication in journalism ethics "seriously belies Aristotle's intent." Cunningham critiques media ethics texts for implying that virtuous behavior is essentially avoidance of the extremes, rather than acts

\footnotetext{
${ }^{5}$ Stanley B. Cunningham, "Getting it right: Aristotle's 'golden mean' as theory deterioration," Journal of Mass Media Ethics 14.1 (1999): 14, 5.
} 
chosen for their own goodness or merit. Additionally, he claims that while finding the golden mean between two extremes is a "convenient strategy" for the "conflict-driven view of ethical reasoning" ${ }^{\prime \prime}$ typified by textbook case studies, that strategy seriously undervalues the golden mean as something that "situates the right choice as something issuing from a character-grounded vision of what ought to be done, a selection that is constituted by the wisdom-enhanced judgment of a morally developed actor."”

On the whole, I agree with Cunningham's account of Aristotle and his assessment of the problem, but in this paper I offer a specific approach to more authentically integrating virtue ethics into an undergraduate media ethics classroom. I will say more about what I see as the problem with students' application of Aristotle and how they might avoid it, but first I want to consider what they might be learning about the golden mean and what might lead them toward this misapplication.

\section{$\underline{\text { Aristotle in media ethics textbooks }}$}

Some students of media ethics have been exposed to Aristotle's work on moral philosophy through reading his primary text, The Nicomachean Ethics, in a philosophy course. This is the case at my university, for example, where an introductory ethics course is part of the core curriculum. Most media students, however, are introduced to Aristotle and the golden mean through media ethics textbooks. In the space of a few pages, many textbook authors do an admirable job of representing Aristotle's ideas as accurately as possible.

\footnotetext{
${ }^{6}$ Stanley B. Cunningham, “Getting it right: Aristotle's 'golden mean' as theory deterioration," Journal of Mass Media Ethics 14.1 (1999): 10-11.

${ }^{7}$ Ibid., 11.
} 
In Media Ethics: Issues and Cases, Philip Patterson and Lee Wilkins describe

Aristotle's virtue ethics as a system that

flows from both the nature of the act itself and the moral character of the person who acts. In the Aristotelian sense, the way to behave ethically is that (1) you must know (through the exercise of practical reason) what you are doing; (2) you must select the act for its own sake - in order to flourish; and (3) the act itself must spring from a firm and unchanging character. ${ }^{8}$

Patterson and Wilkins go on to explain that Aristotle's philosophy is often reduced to the "somewhat simplistic golden mean," 9 and they note that virtue lies at the mean between two extremes: excess and deficiency. They also point out the agent-centeredness of Aristotelian thought: "A virtue theory of ethics is not outcome-oriented. Instead, it is agent-oriented, and right actions in a virtue theory of ethics are a result of an agent seeking virtue and accomplishing it." 10

In their discussion of Aristotle in Media Ethics: Cases and Moral Reasoning, Clifford G. Christians, Kim B. Rotzoll, Mark Fackler, Kathy Brittain McKee and Robert H. Woods, Jr. note, "Whereas many ethical theories focus on behavior, Aristotle emphasizes character rather than conduct per se. Outer behavior, in his view, reflects our inner disposition." 11 The authors rightly attribute the concept of the golden mean to Confucius, who-150 years before Aristotle — rooted his ethical theory in virtue. Christians and his colleagues do, however, discuss Aristotle's doctrine of the mean and use his own words: "Moral virtue is a fixed quality of the will, consisting essentially in a middle state, as determined by the standard that a person of practical wisdom would

\footnotetext{
${ }^{8}$ Philip Patterson and Lee Wilkins, Media ethics: Issues and cases, $6^{\text {th }}$ ed. (Boston: McGraw Hill, 2008): 8. ${ }^{9}$ Ibid., 8.

${ }^{10}$ Ibid., 9 .

${ }^{11}$ Clifford G. Christians, Kim B. Rotzoll, Mark Fackler, Kathy Brittain McKee, and Robert H. Woods, Jr., Media Ethics: Cases and Moral Reasoning, $7^{\text {th }}$ ed. (Boston: Pearson Education, Inc., 2005): 12.
} 
apply." ${ }^{12}$ Borrowing from Cunningham, the authors argue that through a lifetime of moral growth and the acquisition of moral virtues, individuals develop a disposition "toward the virtuous mark in our choices."

Authors of communication ethics texts—as opposed to media ethics texts - treat Aristotle similarly. Richard L. Johannesen, for example, describes Aristotle's doctrine of the mean this way:

For Aristotle, moral virtue usually represents a mean or intermediate point between two vices - the vice of excess and the vice of deficiency...Aristotle denies that the mean is a mathematically precise average or midpoint between extremes. Rather the mean combines the right amount at the right time toward the right people in a right manner for the right motives. The mean is also relative to the person's status, specific situation, and strengths or weaknesses of character. ${ }^{14}$

Eight pages later, Johannesen — again borrowing Cunningham's words—notes that “a person of sound moral character generally lives a life of right action.," ${ }^{, 15}$ In other words, a virtuous person knows what to do.

And finally, to William W. Neher and Paul J. Sandin's treatment of Aristotle in Communicating Ethically. As they note, "The essential point about Aristotle's system of ethics is that character is the most important defining feature of ethical conduct." Character, the authors explain, is cultivated by practicing the moral virtues, which are equated with excellence and which represent the mean between two extremes. In their discussion of contemporary virtue ethics, Neher and Sandin attempt to clarify the concept further by adding that "a behavior is right or ethical because of the character of the person

\footnotetext{
${ }^{12}$ Aristotle, cited in Clifford G. Christians, Kim B. Rotzoll, Mark Fackler, Kathy Brittain McKee, and Robert H. Woods, Jr., Media Ethics: Cases and Moral Reasoning, $7^{\text {th }}$ ed. (Boston: Pearson Education, Inc., 2005): 12 .

${ }^{13}$ Cunningham, cited in Christians, et. al, 13.

${ }^{14}$ Richard L. Johannesen, Ethics in Human Communication, $5^{\text {th }}$ ed. (Long Grove, IL: Waveland Press, Inc., 2002): 4.

${ }^{15}$ Cunningham, cited in Johannesen, 12.

${ }^{16}$ William W. Neher and Paul J. Sandin, Communicating Ethically: Character, Duties, Consequences, and Relationships (Boston: Pearson Education, Inc., 2007): 23.
} 
performing it. A person is not virtuous or ethical because they perform certain right actions, but it is the other way around. The action is virtuous because of the nature of the person who performs it.",17

In his evaluation of media and communication ethics texts (editions published between 1991 and 1997), Cunningham critiqued them for giving a "misplaced conceptual priority to the extremes," where virtuous behavior is essentially avoidance of the extremes; "one arrives at the midpoint by first perceiving or envisaging extremes, avoiding them and negotiating a passage between them." ${ }^{\text {18 }}$ I don't share this criticism with Cunningham. In reviewing more recent editions of media and communication ethics texts, a few of which cite Cunningham's 1999 article, some of them do contain passages that focus on the mean as a particular action, which falls between two other actions at the extremes. ${ }^{19}$ But I don't find the same kind of conceptual prioritizing of the extremes that Cunningham criticizes. Instead, the overall emphasis seems to reflect Aristotle's focus on developing a virtuous character, which is crucial to understanding Aristotle's theoretical approach. ${ }^{20}$

Yet, even with textbooks' focus on character and being, students are still inclined to use the golden mean as a formula for guiding action. They read textbook passagesand listen to their professors - explaining Aristotle's emphasis on virtue, but then when it

\footnotetext{
${ }^{17}$ William W. Neher and Paul J. Sandin, Communicating Ethically: Character, Duties, Consequences, and Relationships (Boston: Pearson Education, Inc., 2007): 26.

${ }^{18}$ Stanley B. Cunningham, "Getting it right: Aristotle's 'golden mean' as theory deterioration," Journal of Mass Media Ethics 14.1 (1999): 7.

${ }^{19}$ For example, Christians et. al note that finding "the middle state mean" is the best option for acting in cases like alcohol advertising where one extreme would be not allowing advertising at all and the other would be no restrictions on it whatsoever.

${ }^{20}$ It is important to note that, in their discussion of Aristotle, some authors do focus on virtuous action, rather than on virtuous character. This misapplication can be seen, for example, in Kirk Hallahan's chapter "Responsible online communication" (Kathy Fitzpatrick and Carolyn Bronstein, eds. Ethics in Public Relations: Responsible Advocacy, Thousand Oaks, CA: Sage, 2006). On page 120 Hallahan notes, "Aristotle's principle of the 'golden mean' suggested that in every situation there are two extremes and the ethical choice is in the middle."
} 
comes time to think about applying Aristotle's work, they want to look for the action that falls in the golden mean.

This inclination makes sense. Applied ethics courses are all about deciding how to act; they spend a good deal of time helping students develop tools to figure out what to do when they're confronted with ethical issues in their professional lives. Put simply, applied ethics courses tend to be much more about doing than about being, and in my experience, it's the doing part that seems best to incite passion in students - to stimulate their moral imaginations. ${ }^{21}$

But when students try to use Aristotle's golden mean to make decisions about behaviors, the analyses usually look something like the example of the L.A. Gay and Lesbian Center ad campaign introduced above. In this case and in countless others I've heard being analyzed from an Aristotelian perspective, students identify one extreme that involves acting (running the campaign, doing the story, taking the photo, etc.), which is defined as the excess, and the other extreme that involves not acting (not running the campaign, holding the story, putting the camera down), which is defined as the deficiency. The mean, then, always involves an adjusted — usually watered-downversion of the proposed action. When the extremes are defined as doing something or not doing it, the midpoint always involves action. Anything more excessive than not acting involves some kind of action. It's like a midpoint between standing still and running;

\footnotetext{
${ }^{21}$ Stimulating the moral imagination is one of five goals for teaching ethics proposed by the Hastings Center in 1980. See Daniel Callahan and Sissela Bok, Eds., Ethics Teaching in Higher Education (New York: Plenum Press, 1980).
} 
anything between the two will always involve movement. ${ }^{22}$ The problem, however, is that action - in any form - may not align with being virtuous.

So asking the question, "What action represents the golden mean?" privileges action. But this is not my biggest critique of this kind of analysis. The essential problem is that students are asking the wrong question. The doctrine of the mean is about character traits or virtues, not about actions. Aristotle's famous list of virtues includesamong others - courage, temperance, liberality, patience, truthfulness and modesty. ${ }^{23}$ To this list of the classic virtues, others have added dispositions particular to specific professions. Stephen Klaidman and Tom L. Beauchamp, for example, name the following virtues for journalists: fairness, truthfulness, trustworthiness and nonmalevolence. ${ }^{24}$ Alternatively, Aaron Quinn emphasizes journalistic virtues of justice and integrity. ${ }^{25}$ For public relations professionals, Thomas Bivins lists truthfulness, loyalty, trustworthiness, honesty, diligence and discretion; for advertising it is truthfulness, loyalty, diligence, honesty and tactfulness. ${ }^{26}$ And for business, Robert Solomon includes honesty, fairness, trust, toughness, honor, loyalty and friendliness. ${ }^{27}$ Whatever the list of virtues, it is Aristotle's claim that a person who has developed virtues (character traits that represent the mean between extremes) will know

\footnotetext{
${ }^{22}$ Here, I intentionally say " $a$ midpoint" rather than "the midpoint" because the mean is not defined as the mathematical middle.

${ }^{23}$ Aristotle, The Nicomachean Ethics, J.A.K. Thomson, trans. (London: Penguin Books, 1953): 104

${ }^{24}$ Stephen Klaidman and Tom L. Beauchamp, The Virtuous Journalist (New York: Oxford University Press, 1987). In the introductory chapter of their text, Klaidman and Beauchamp note that the table of contents provides a list of the major virtues they believe essential to journalists. The chapter titles, however, speak to actions: "Reaching for Truth," "Avoiding Bias," "Avoiding Harm," "Serving the Public," Maintaining Trust," "Escaping Manipulation," and "Inviting Criticism and Being Accountable." This is one example of the misuse of the concept of virtue.

${ }^{25}$ Aaron Quinn, "Moral virtues for journalists," Journal of Mass Media Ethics, 22.2/3 (2007): 168-186.

${ }^{26}$ Thomas H. Bivins, Mixed Media: Moral Distinctions in Advertising, Public Relations and Journalism (Mahwah, NJ: Lawrence Erlbaum Associates, 2004).

${ }^{27}$ Robert Solomon, Ethics and Excellence: Cooperation and Integrity in Business (New York: Oxford University Press, 1992).
} 
what to do when faced with an ethical issue, whether this is acting or, perhaps, not acting. The virtuous person will "feel or act towards the right person to the right extent at the right time for the right reason in the right way., ${ }^{28}$

"Great," my students say. "A virtuous person will do the right thing. How does that help us figure out what to do?" The attraction to a question like, "What action represents the golden mean?" is that it seems to deal more concretely with dilemmas in applied ethics. Like the categorical imperative or the utility calculus, it gives a kind of formula that provides guidance for acting. But the golden mean question is still the wrong one. What, then, is the right question?

\section{Asking the right question}

In a semester-long media ethics class, students can't be expected to master the full intricacies of Aristotle's ideas, but his work can still help inform students' analyses and help them build strongly justifiable arguments. In teaching Aristotle, I focus on the idea of virtues, what they are and how they are developed. While I do explain that virtues are character traits that fall between traits of excess and deficiency, the golden mean never enters into the discussion. Instead, I ask students to pose this Aristotelian question: What action aligns with being virtuous. Put another way: What does it mean to be courageous, loyal, trustworthy, etc. in this situation? This question, I find, tends to keep students away from a purely action-oriented consideration of Aristotle and brings the focus back to character and being (which then can inform action).

Because I am a pluralist when it comes to ethical theory and because I try to foster in students the same attitude, it's important to explain how Aristotle's ideas fit into a

\footnotetext{
${ }^{28}$ Aristotle, The Nicomachean Ethics, J.A.K. Thomson, trans. (London: Penguin Books, 1953): 109.
} 
larger approach to ethical analysis that I introduce to students. This approach is illustrated by the diagram below.

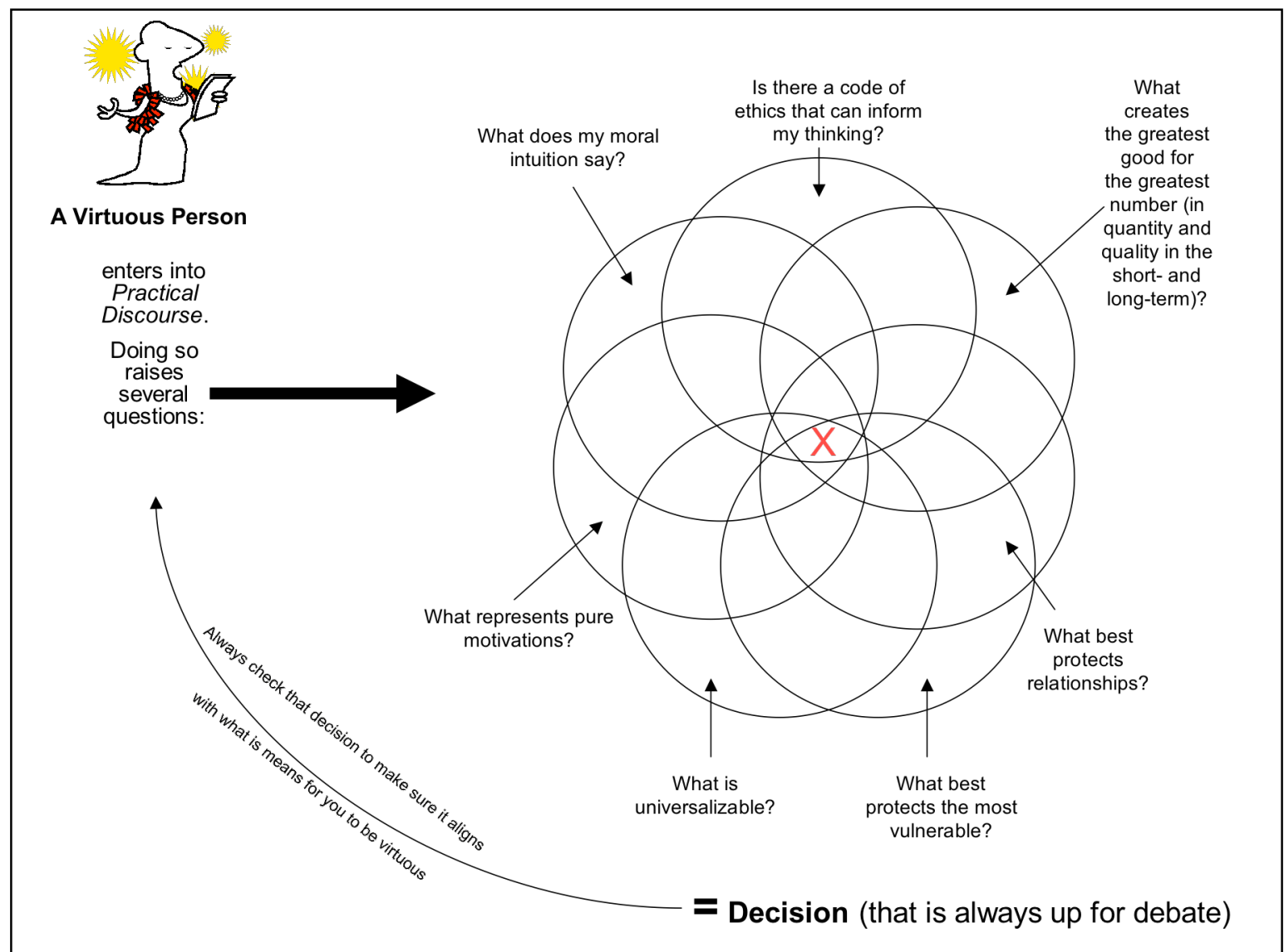

Figure 1. Integrating Aristotle's virtue ethics in moral analysis.

Through this approach, students (and all moral agents) are encouraged to bring to bear as many tools as they have at their disposal when analyzing an ethical issue. Doing so helps lead to the most ethically justifiable decision. The approach begins with the idea that students enter into ethical deliberation as virtuous people who have developed traits of good character; these virtues inform their thinking throughout the entire process. Because I also introduce Habermas in my classes and stress the importance of engagement - rather than only reflection — with ethical issues, the process of deliberation 
or discourse is referred to in the diagram as practical discourse. ${ }^{29}$ During the discourse, students can raise a number of questions about potential options for acting, including questions prompted by moral intuition, by professional codes and conventions and by other theorists. For example, the diagram includes theoretical questions stemming from Mill's utilitarianism, Kant's categorical imperative, Gilligan's ethics of care, and Rawls' theory of justice. Clearly, the number of questions that can be posed is limitless, and different cases may call for specific questions germane to that particular case. An option that satisfies the requirements of all questions (one that aligns with moral intuition, the relevant code of ethics, and the theoretical perspectives) is the ideal. This is represented by the red " $X$ " in the diagram. Of course, ethical dilemmas are often more thorny than this, and an ideal option is just that: ideal. When different questions lead students toward different options, they then must decide which justifications trump others in the particular situation. They must also be able to explain why they are privileging some values or principles at the expense of others.

In the end, when students arrive at a decision, they return to Aristotle and ask, "Does my decision align with what it means to be courageous, loyal, honest, trustworthy, etc.? ${ }^{, 30}$ Capping off the analysis with this question brings the process back to Aristotle where it started and gives a final virtue-based check to the decision.

Some may argue that this approach oversimplifies ethical theory and leads to the morality-by-slogan approach I criticized at the beginning of this essay. I recognize some

\footnotetext{
${ }^{29}$ Practical discourse is a term specific to Habermas; for classes that don't explore his ideas particularly, the diagram could simply be labeled "deliberation."

${ }^{30}$ If students are analyzing the case from a first-person perspective-if they have been asked what they would do in the case - they would pose the question: "Does my decision align with what it means for $m e$ to be virtuous?" This allows for the individual nature of virtues and the idea that courage, loyalty, honesty, trustworthiness, etc. are not the same for every person. Alternatively, if students are doing a third-person analysis (i.e. what should the journalist do?), they can look to the individual virtues identified for journalists as professionals as well as to the collective virtues of the profession.
} 
validity in this criticism but argue that, even if the approach over-simplifies Aristotle (and other moral philosophers), it does move the Aristotelian considerations back into the proper realm of being and away from the misplaced "golden mean" of acting. Although, as I noted earlier, I'm an advocate for mixed pluralism, this approach also permits a purely Aristotelian analysis of a dilemma. When confronted with a dilemma, students can pose the key Aristotelian question at the beginning of the analysis and work from there: What does it mean to be virtuous (courageous, honest, loyal) in this situation? In keeping with the individual nature of virtues, this question allows for an answer that satisfies the call to be virtuous while also recognizing that virtue may be expressed in different ways by different people. ${ }^{31}$

\section{$\underline{\text { Applying Aristotle }}$}

Let's revisit the case introduced at the beginning of this paper and examine one analysis by students that more authentically applies Aristotle's virtue ethics. In this case, recall that the Los Angeles Gay and Lesbian Center had introduced an advertising campaign with the headline and tagline "HIV is a gay disease. Own it. End it." A proper Aristotelian analysis of this case would not call for determining the golden mean but rather for ensuring that any chosen action (or lack of action) aligns with what it means to be virtuous for those creating and running the campaign. If students were to refer back to the list of virtues that Bivins presented for advertisers, in doing their analysis they would have to decide what it would mean to be truthful, loyal, diligent, honest and tactful.

\footnotetext{
${ }^{31}$ Aristotle emphasizes that the mean is not the same for all people. On page 100 of Nicomachean Ethics, he states, "Every knowledgeable person avoids excess and deficiency, but looks for the mean and chooses it - not the mean of the thing, but the mean relative to us." (London: Penguin Books, 1953).
} 
Unlike students who have applied the "golden mean" test to this case and come up with a solution that involves doing the campaign in a modified, "less controversial" way (because the mean between action and inaction is always some kind of action), those who have approached the case from a perspective of aligning their decision with being virtuous have arrived at a decision that the campaign is ethically unjustifiable. Although the campaign may represent diligence on the part of those behind it, going forward with the campaign is not truthful or honest: HIV is not a gay disease. ${ }^{32}$ Second, the campaign does not align with being loyal to members of the L.A. lesbian and gay community or with others who might see the campaign. And finally, it does not represent tact; in fact, the opposite can be said. The campaign is designed to shock people into action, to purposefully offend their sensibilities. This lack of tact can be seen in many real responses to the campaign. Consider, for example, this post on the Web site

\section{LAVoice.org:}

HIV is a Gay disease? Are you kidding? For those of us living with the shame and fear of being HIV positive, I'm angry. For those who've lived long enough to see the world begin to accept HIV as more then [sic] a gay disease, I'm offended. For those who expect more from our gay organizations, I'm disappointed. Most people will only read your flashy tag line and that's what they'll promote. This world is filled with misinformation, due to our short attention spans. Most people get there $[\mathrm{sic}]$ information from bits and pieces propagated by the evening news or a flashy headline. I expected more from your center. While the details of your ad are most likely accurate, you've done an injustice to your community. You've flown off course and I'm saddened by your decision to promote this hateful headline. ${ }^{33}$

In the end, students who have asked the Aristotelian question "Does the 'Own it. End it' campaign align with what it means for advertisers to be virtuous?" conclude that it does

\footnotetext{
${ }^{32}$ According to a Sept. 30, 2006, Los Angeles Times article by Sharon Bernstein, "Nationwide, gay and bisexual men account for just $45 \%$ to $50 \%$ of recent HIV transmission, according to the national Centers for Disease Control and Prevention in Atlanta." (HIV Ads Embrace, and Stun, Audience, p. A1

33 "Agents Provocateurs: LAGLC Says 'HIV *IS* a "Gay Disease,'” LAVoice.org, (2 Oct., 2006), 21 March, $2008<$ http://lavoice.org/index.php?name=News\&file=article\&sid=2252>
} 
not. Many of the important virtues that should characterize advertising professionals are not expressed through this particular campaign, and the campaign as presented is out of character for a virtuous person.

\section{$\underline{\text { Neo-Aristotelian Perspectives }}$}

The approach that I advocate in this paper need not be limited to Aristotle, although his work is the most frequently cited example of virtue-based theories in media ethics courses. For example, the neo-Aristotelian theory of Alasdair MacIntyre can accommodate a similar key question to the one I pose for Aristotle: What action aligns with being virtuous? For MacIntyre, particular roles, such as the role of journalist, are defined by participation in communal activities known as practices, yet successful engagement in a practice requires traits of good character. In other words, practices are the context for the exercise of virtue. ${ }^{34}$ On a collective level, then, media ethics students can ask whether the performance of journalists as a whole (or advertisers, or public relations professionals) aligns with what virtue would require: Are journalists as a collective engaging in practices that are guided by virtue and directed toward an intrinsic good?

At the outset of this paper, I referred to Bernard Gert's article, "Morality versus Slogans." Gert began his own paper by stating, "I am not going to say anything that everyone doesn't already know. I think of myself as simply making explicit some points that people may have overlooked, and clarifying some points that are confusing because

\footnotetext{
${ }^{34}$ Sandra L. Borden and Chad Tew, "The role of journalist and the performance of journalism: Ethical lessons from "fake news" (seriously)," Journal of Mass Media Ethics, 22.4 (2007): 300-314.
} 
people may not have taken enough time to think about them sufficiently." 35 Gert may have seriously underestimated the power of his work; the "moral rules" he presents in "Morality versus Slogans" have been widely used by applied ethicists. On the other hand, I truly believe that my paper isn't introducing new ideas. Readers of this essay, who are likely ethicists themselves, understand the tenets of virtue ethics and its focus on character and being. They understand that the golden mean refers to identifying virtues and not choosing actions. But if any readers are like me, they have also struggled with helping undergraduate students apply these ideas in a practical ethics context where the focus is so often on doing. It is my hope that sharing this framework for applying Aristotle offers one strategy that media ethics professors can use to help foster in their students better theoretical literacy and better analytical skills, which eventually lead to more strongly justifiable decisions.

\footnotetext{
${ }^{35}$ Bernard Gert, Morality versus Slogans (Paper Presented to the Center for the Study of Ethics in Society, Western Michigan University, Kalamazoo, Michigan, 1989): $\uparrow 1$.
} 